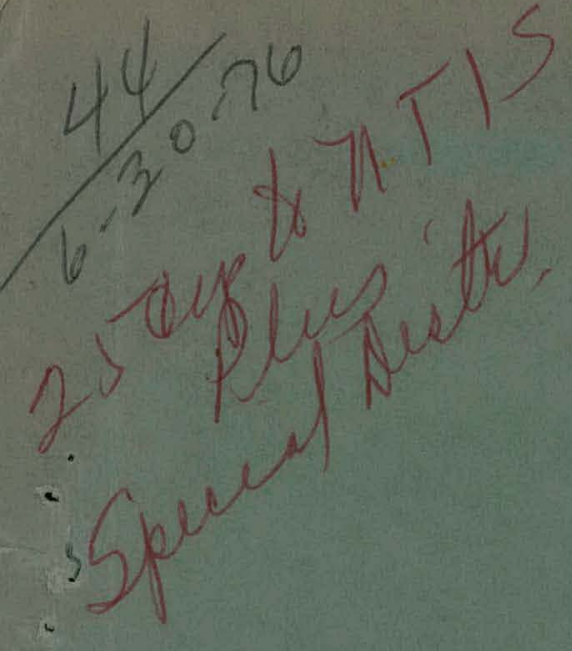

BNWL-1954

\title{
Automatic Fire Hydrant Valve Development
}

January 1976

Prepared for the U.S. Energy

Research and Development Administration

under Contract E(45-1):1830 


\section{DISCLAIMER}

This report was prepared as an account of work sponsored by an agency of the United States Government. Neither the United States Government nor any agency Thereof, nor any of their employees, makes any warranty, express or implied, or assumes any legal liability or responsibility for the accuracy, completeness, or usefulness of any information, apparatus, product, or process disclosed, or represents that its use would not infringe privately owned rights. Reference herein to any specific commercial product, process, or service by trade name, trademark, manufacturer, or otherwise does not necessarily constitute or imply its endorsement, recommendation, or favoring by the United States Government or any agency thereof. The views and opinions of authors expressed herein do not necessarily state or reflect those of the United States Government or any agency thereof. 


\section{DISCLAIMER}

Portions of this document may be illegible in electronic image products. Images are produced from the best available original document. 
NOTICE

This report was prepared as an account of work sponsored by the United States Government. Neither the United States nor the Energy Research and Development Administration, nor any of their employees, nor any of their contractors, subcontractors, or their employees, makes any warranty, express or implied, or assumes any legal liability or responsibility for the accuracy, completeness or usefulness of any imformation, apparatus, product or process disclosed, or represents that its use would not infringe privately owned rights.

PACIFIC NORTHWEST LABORATORY

operated by

BATTELLE

for the

ENERGY RESEARCH AND DEVELOPMENT ADMINISTRATION

Under Contract E(45-1)-1830

\author{
Printed in the United States of America \\ Available from \\ National Technical Information Service \\ U.S. Department of Commerce \\ 5285 Port Royal Road \\ Springfield, Virginia 22151 \\ Price: Printed Copy $\$ 5.00$; Microfiche $\$ 2.25$ \\ 4.2
}




\section{AUTOMATIC FIRE HYDRANT VALVE DEVELOPMENT}

BY

K. DRUMHELLER

January 1976

BATTELLE-NORTHWEST

RICHLAND, WASHINGTON 99352

DISTRIBUTION OE JHUS DOCUMENT IS INLAMITED $=$ 


\section{CONTENTS}

LIST OF FIGURES

1.0 SUMMARY

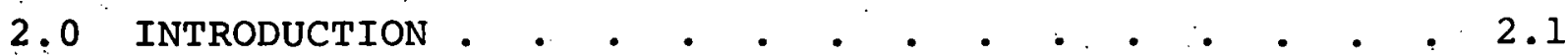

3.0 PROBLEM STATEMENT

4.0 DESIGN CONSIDERATIONS . . . . . . . . . . . . . 4.1

4.1 Concept Considerations . . . . . . . . . . . . . . . .

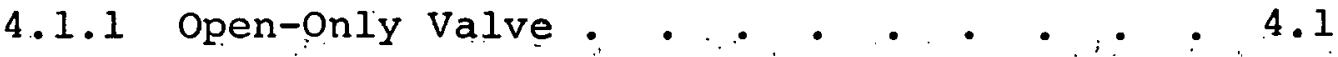

4.1 .2 Open and Close Valve . . . . . . . 4.3

4.1.3, Hydrant Actuator . . . . . . . . . 4.3

4.2 Advantages and Disadvantages of Each . 4.3

of the. Three Approaches

4.2 .1 Open-Only . . . . . . . . . . . . . 4.3

4.2 .2 Open and Close . . . . . . . . . 4.6

4.2.3 Hydrant Operator . . . . . . . . 4.7

5.0 DESIGN APPROACH • . . . . . . . . . . . . . . 5.1

5.1 First Approach • • • • • • • • . . . 5.1

5.2 Second Approach . . . . . . . . . . . 5.4

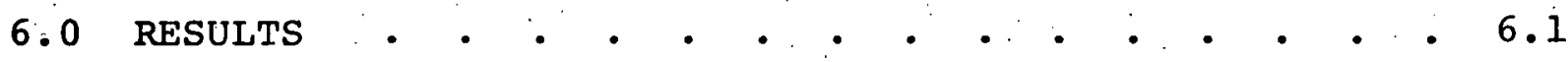

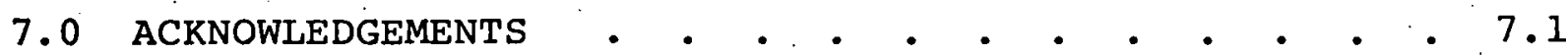




\section{LIST OF FIGURES}

1 . Remotely Controlled Hydrant Valve . . . . . . . . 2.2

2 Quick Opening Valve . . . . . . . . . 4.2

3 Remote Controlied valive . . . . . . . . . 44

4. Hydrant Operator . . . . . . . . . . . . . 4.5

5. Operational Set-up for Remotely-Controlled Fire Hydrant Valve . . . . . . . . . . . . . 5.2

6 Remotely-Controlled Hydrant Valve--First Approach. . 5.3

7 Schematic Description of Hydrant Valve . . . . . . 5.6

8 Operation Schematic--Hydrant Valve $\because . . . .5 .7$ 


\section{AUTOMATIC FIRE HYDRANT VALVE DEVELOPMENT}

\subsection{SUMMARY}

This report details the development of a remotely-controlled valve to operate a fire hydrant. Assembled from off-the-shelf components, the prototype illustrates that a valve light enough to be handled by one man is possible.: However, it does not have the ruggedness or reliability needed for actual fire-fighting operations. Preliminary testing by City of Tacoma fire department personnel indicates that the valve may indeed contribute significantly to fire-fighting efficiency. 


\subsection{INTRODUCTION}

This program was sponsored as part of a Battelle Pacific Northwest Laboratory - ERDA Office of Industry and State and Local Government Relations program to apply nuclear-industrial technology to urban problems. City of Tacoma personnel, having already been involved with similar applied technology programs were willing to participate in this project. They suggested that a remotely-operated fire hydrant valve could be a potentially useful device.

The valve developed is shown in Figure 1. The basic purpose of our work was to demonstrate that the hydrant valve was functional. We hope that industry will further develop the valve as a commercial item. 


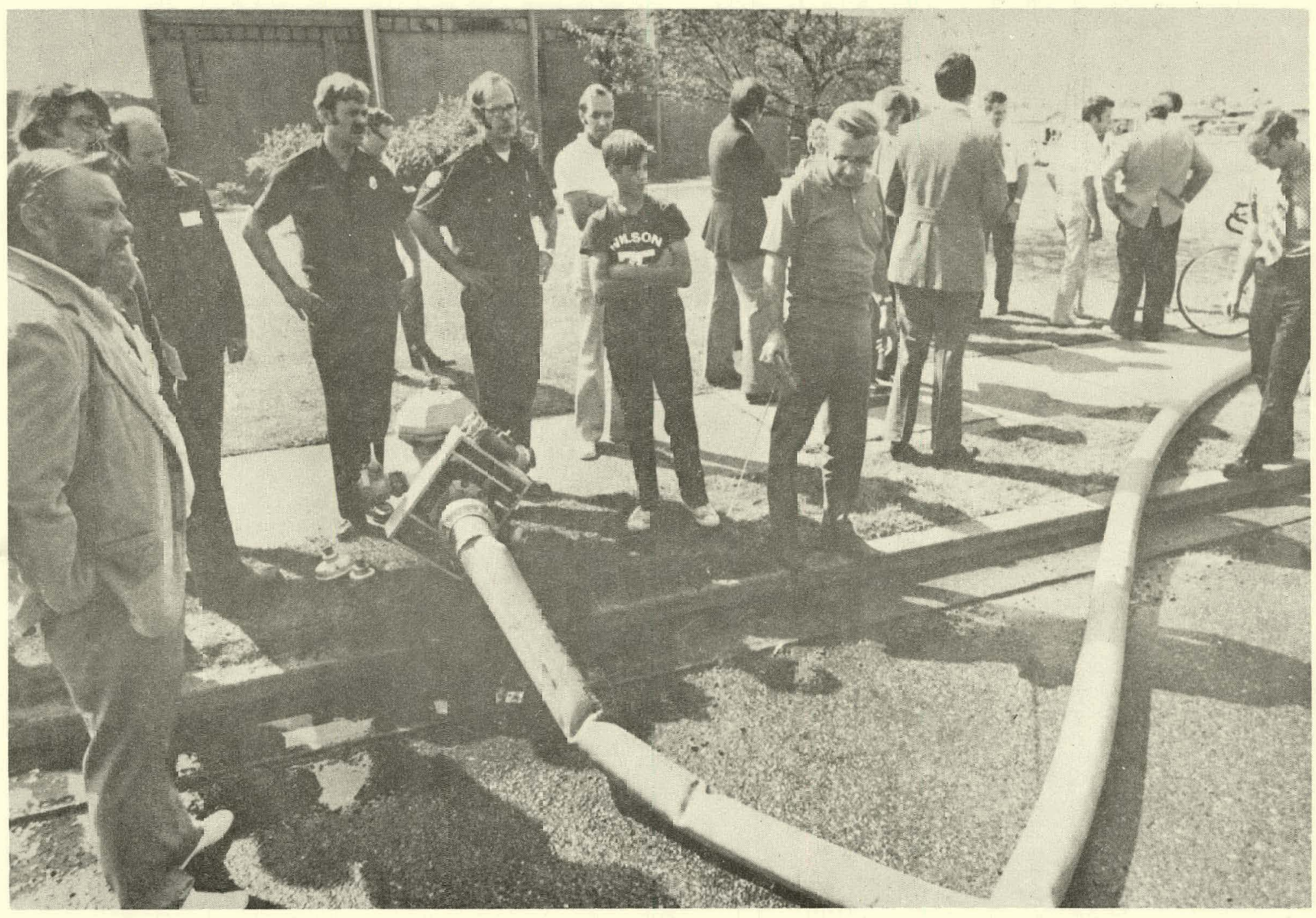

FIGURE 1. Remotely Controlled Hycrant Valve 


\section{0 PROBLEM STATEMENT}

The principal purpose of the hydrant valve is to permit remote operation of a fire hydrant. If a remote operator can be a part of a hydrant or can be quickly enough attached, then a man can be available to set up equipment at the pumper, who might otherwise be required to stand at the hydrant.

A remote valve can be particularly useful in an operation which uses a connector (such as a large-diameter light-weight hose) between the hydrant and pumper and locates the pumper some distance from the hydrant. With this equipment, the pumper can stop for a matter of seconds at the hydrant, install the hydrant valve, open the hydrant, and connect the large diameter hose. The pumper can then move to a location near the fire, paying out the hose between the hydrant and pumper as it goes. Valve effectiveness may be measured by considering the possible additional time spent by the pumper crew during hydrant hook-up and the time saved by having an extra man working at the pumper.

The valve must be highly reliable, for several reasons. One, a false opening while the pumper is traveling from the hydrant to its working location, with the hose hooked to the open hydrant, could energize the hose while it is still in the pumper. This could cause serious injury and property damage. Two, should the valve not open reliably when required, a man would have to run back from the pumper to the hydrant. Three, in the event of a broken line, reliable closing by the pumper is desirable to reduce pressure loss in the hydrant system as quickly as possible. 


\subsection{DESIGN CONSIDERATIONS.}

Three design approaches were considered. These included a valve that opens orily, a valve which opens and closes, and an operator for the hydrant itself.

\subsection{Concept Descriptions}

\subsubsection{Open-On ly Valve}

The open-only valve is shown in Figure 2. The simplest concept has a split gate hinged from each side so the water pressure will open the valve. The gates are held shut by an explosive bolt. The only mechanism involved is a radio signal receiver with a relay and a battery to heat up the explosive bolt firing filament.

Two or more bolts can be put in series and fired from different circuits to provide almost any degree of redundancy desired.

Explosive bolts of the type contemplated are generally considered as safe for handling as a 22 shell. A very lightweight shielding, 20 gauge sheet metal for example, will reportedly provide complete protection.

This mechanism could probably be designed to weigh less than $201 b$ :

If for any reason explosive bolts are not considered suitable, a trigger mechanism for this valve type could be provided which would operate either directly from a solenoid or from an electrically-operated solenoid valve and water-operated hydraulic cylinder. 


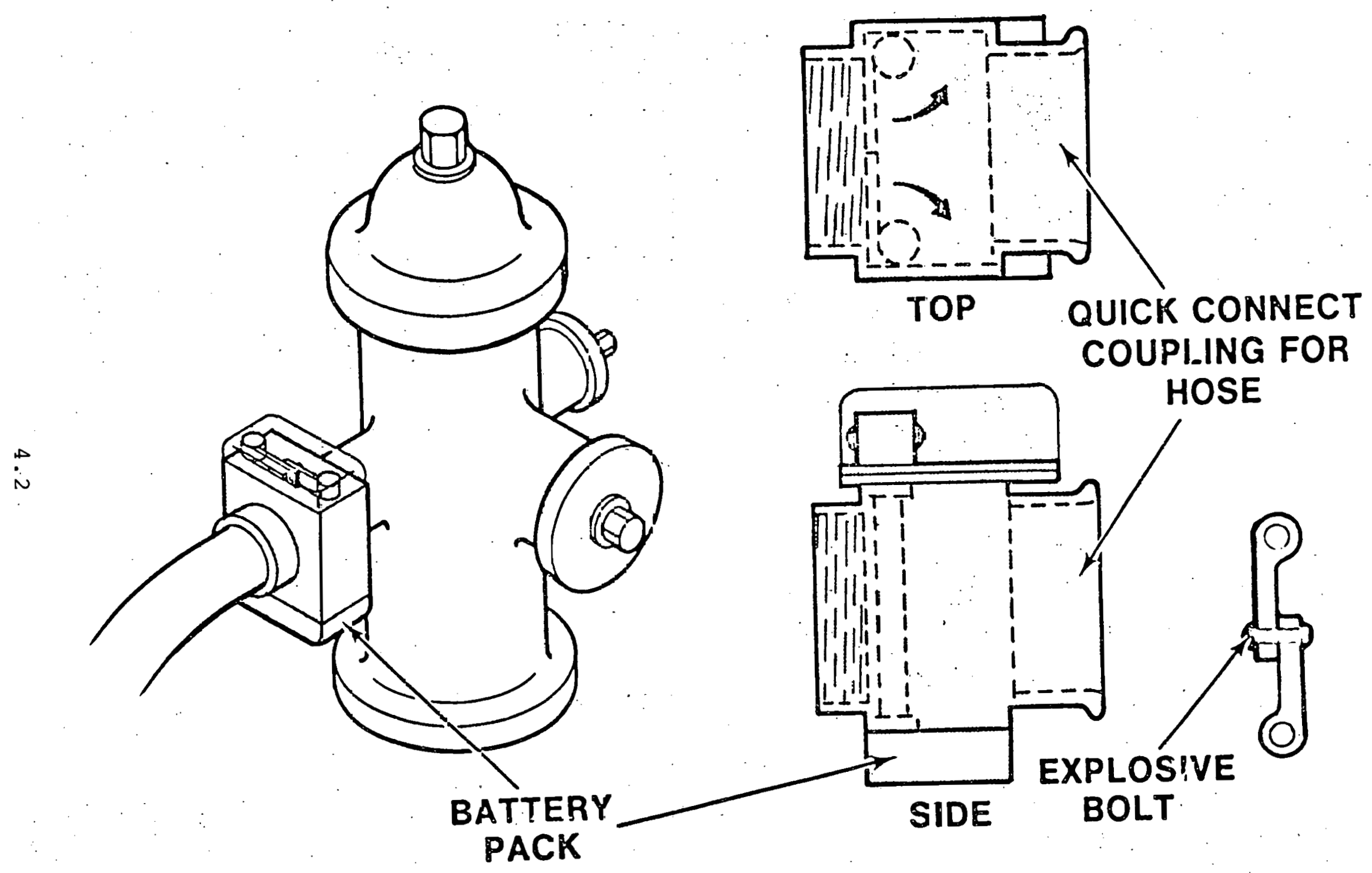

FIGURE 2. Quick Opening Valve 
4.1.2 Open and Close Valve

This valve, illustrated in Figure 3 , uses a conventional butterfly valve with operator. The valve can be sized larger than the pipe if desired to overcome any flow loss from the restriction of the butterfly. The valve is operated by a water. hydraulic cylinder pressurized from the upstream side of the valve or from a self-contained pressure reservoir. The cylinder is controlled by a solenoid valve operated from the radio controls.

This system could weigh from 50 to 100 lb if not attached to the hydrant. If attached directly to the hydrant it should weigh less than $25 \mathrm{lb}$.

\subsubsection{Hydrant Actuator}

The hydrant actuator could be a gear-driven high-torque system comparable to the starter system on an auto engine. Electrically driven impact wrenches were considered, but because of the long stem between the wrench and the valve opening, an impact wrench is not effective.

The hydrant actuator system is shown in Figure 4 ; it should weigh under $50 \mathrm{lb}$.

\subsection{Advantages and Disadvantages of Each of the Three Approaches}

\subsubsection{Open-Only System}

\section{Advantages}

Light Weight. It could probably be designed so the valve can be handled easily and attached directly to the hydrant, simplifying connections, eliminating a potential failure point between the hydrant and the valve, and keeping the valve out of the way and in a position where it is less likely to be damaged by. vehicles. 


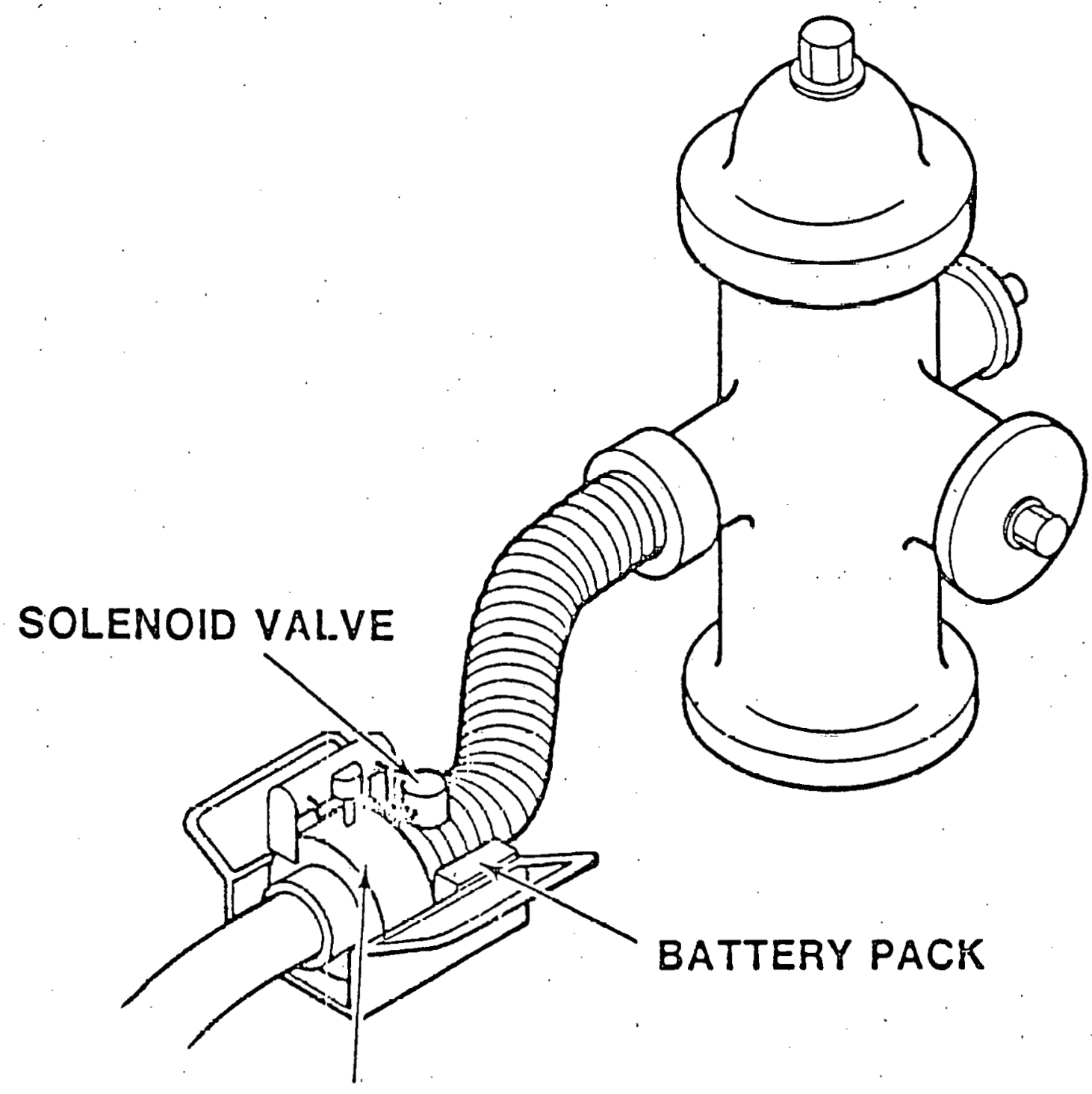

BUTTERFLY VALVE

FIGURE 3. Remote Controlled Valve 


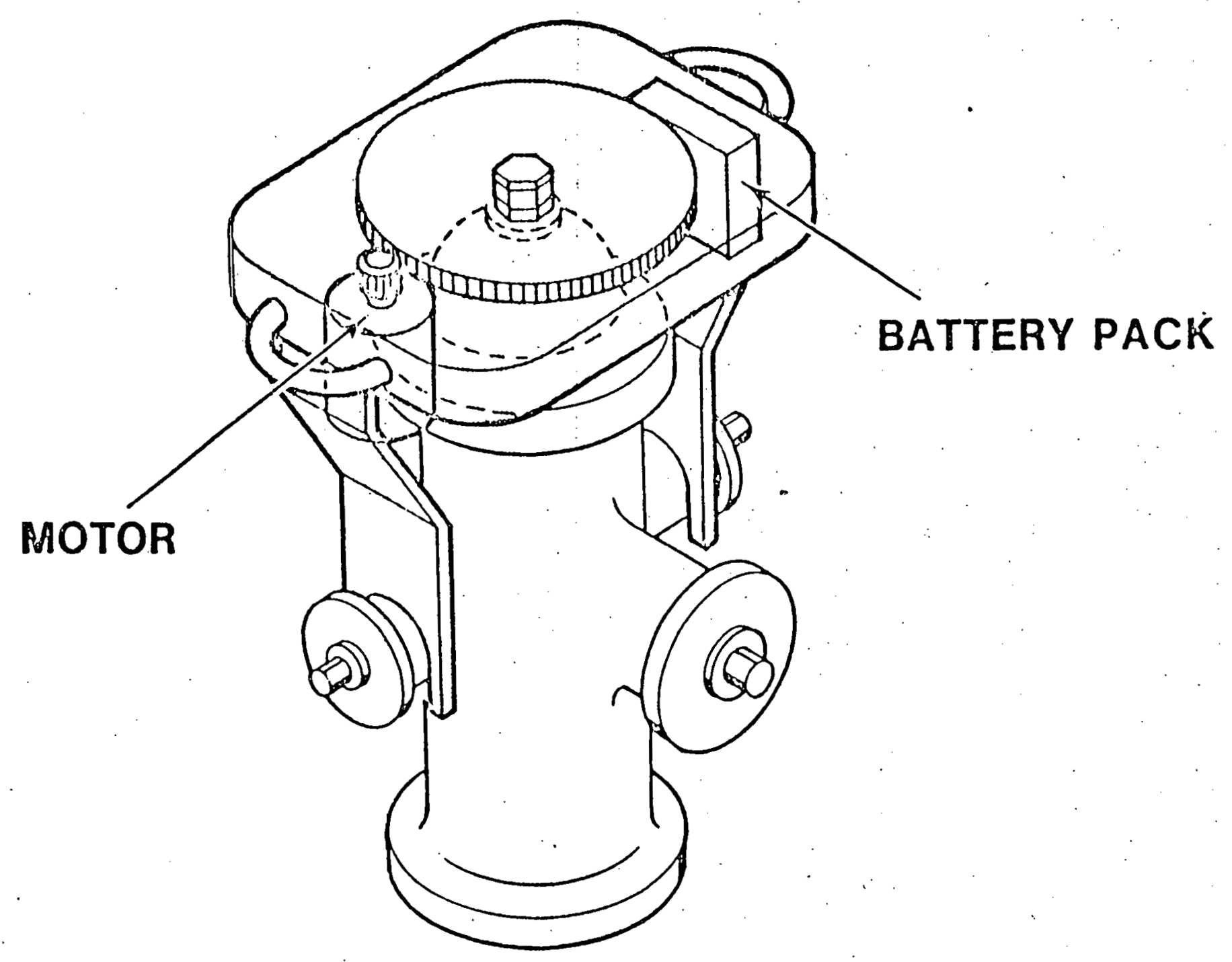

FIGURE 4. Hydrant Operator 
Reliability. An open-only valve can be built so the pressure of the water is the primary opening force. The release mechanism can be very simple. The valve could not accidentally close during operation, and it can be built with several degrees of redundancy in the opening system.

Speed. Because of its light weight and direct hydrant connection, it can be hooked up more rapidly than alternate systems.

\section{Diadvantages}

An open-only valve cannot be closed in the event of a line rupture. It would be necessary to either put a remote closing operator on the hydrant or run back and manually close the hydrant.

\subsubsection{Open and Close System}

\section{Advantages}

The principal advantages are that it will permit remote closing of the hydrant in the event of a line rupture between the hydrant and the pumper. It can also be operated for several cycles.

\section{Disadvantages}

Weight. This valve may be heavier than an open-only valve.

Reliability. With an open-close valve, there is an exceedingly small possibility of accidental closing. The added complexity also reduces reliability to some extent. However, the probability of false operation can be made so small that advantages outweigh this potential disadvantage. 


\subsubsection{Hydrant Operator}

\section{Advantages}

The hydrant operator could possibly be lighter in weight than the remote valve for opening and closing. However, it would be heavier than the remote valve for opening only.

It may be possible to attach the operator more quickly than attaching a valve and opening the hydrant, thus saving time in the total cycle.

Full control would be possible.

\section{Disadvantages}

Reliability. Because of a potentially greater variation in the force required to open and close hydrants, this system is not expected to be as reliable as the open-only valve. It would also probably require some sophisticated controls to stop when the hydrant is fully open or fully closed. 


\subsection{DESIGN APPROACH}

\subsection{First Approach}

Following the above analysis, we concluded that the open and close valve approach could best be applied to demonstrate the principles.

The first approach was to procure a standard hydraulicallyoperated butterfly valve. This valve, in a 4-in. diameter size, was obtained with operator for approximately $\$ 150.00$.

The valve fabrication consisted merely of attaching flanges so the valve could be attached to the hydrant and the hose attached to the valve, and installing a solenoid valve, a garage door control to operate the solenoid valve and a rechargeable gel-type battery.

Pressure to the solenoid valve was provided by means of a hole in the flange on the hydrant side of the valve. With the valve installed the hydrant is opened, providing pressure to the solenoid valve.

The solenoid valve is a $12 \mathrm{~V}$ DC four-way valve which remains in the position in which it was last energized. This latter feature is desirable to minimize battery drain and improve reliability. The solenoid valve provides line pressure to the butterfly valve actuator. The power supply is a lightweight gel-type rechargeable battery.

The garage door opener was a standard garage door opener; the garage door motor operator contact points were used to actuate the solenoid valve.

The valve assembly is illustrated in Figures 5 and 6 . This assembly was installed with temporary wiring and functioned satisfactorily. Because of its weight, approximately $45 \mathrm{lb}$, a lighter system was tried. 


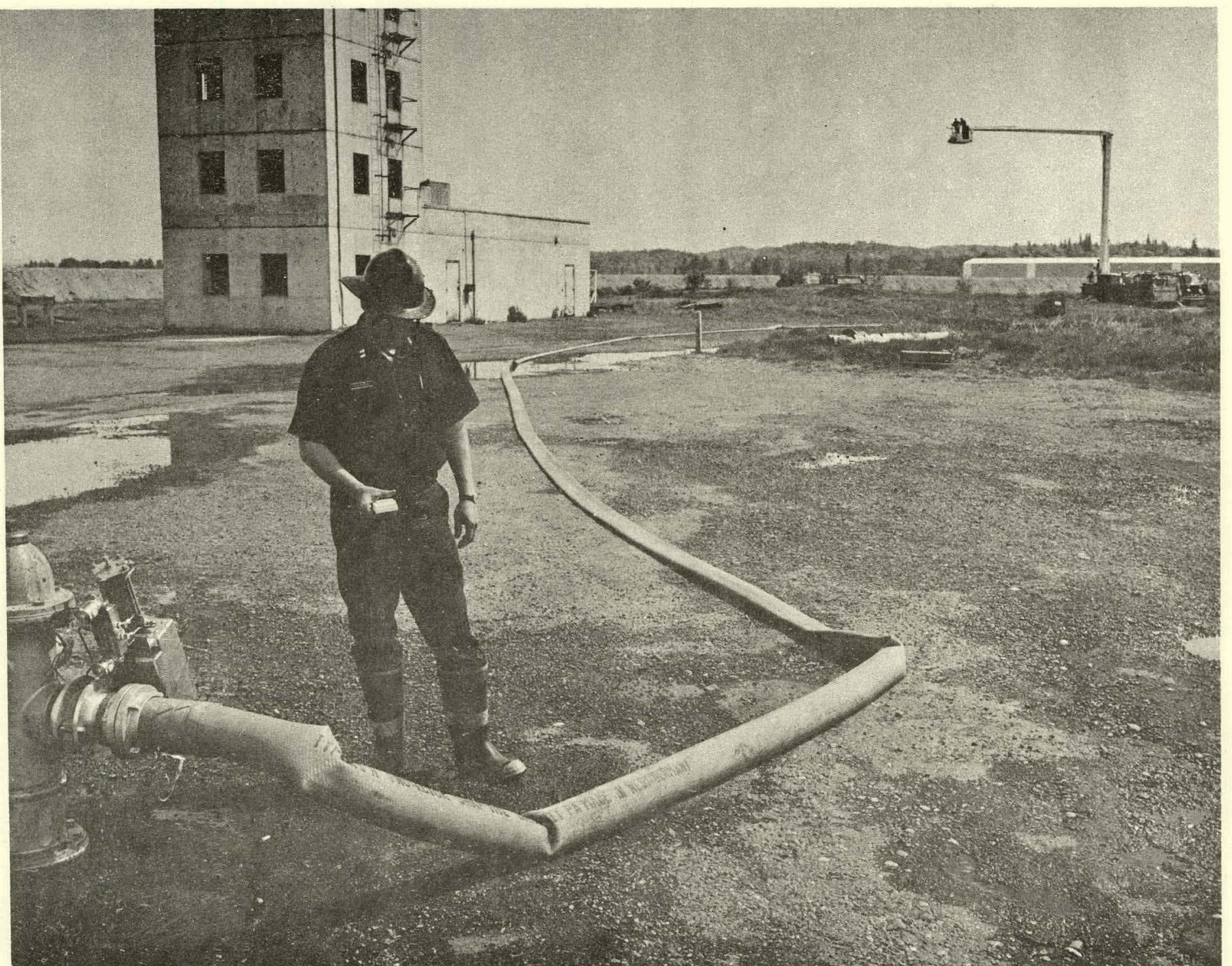

FIGURE 5. Operational Set-Up for Remotely-Controlled Fire Hydrant Valve 


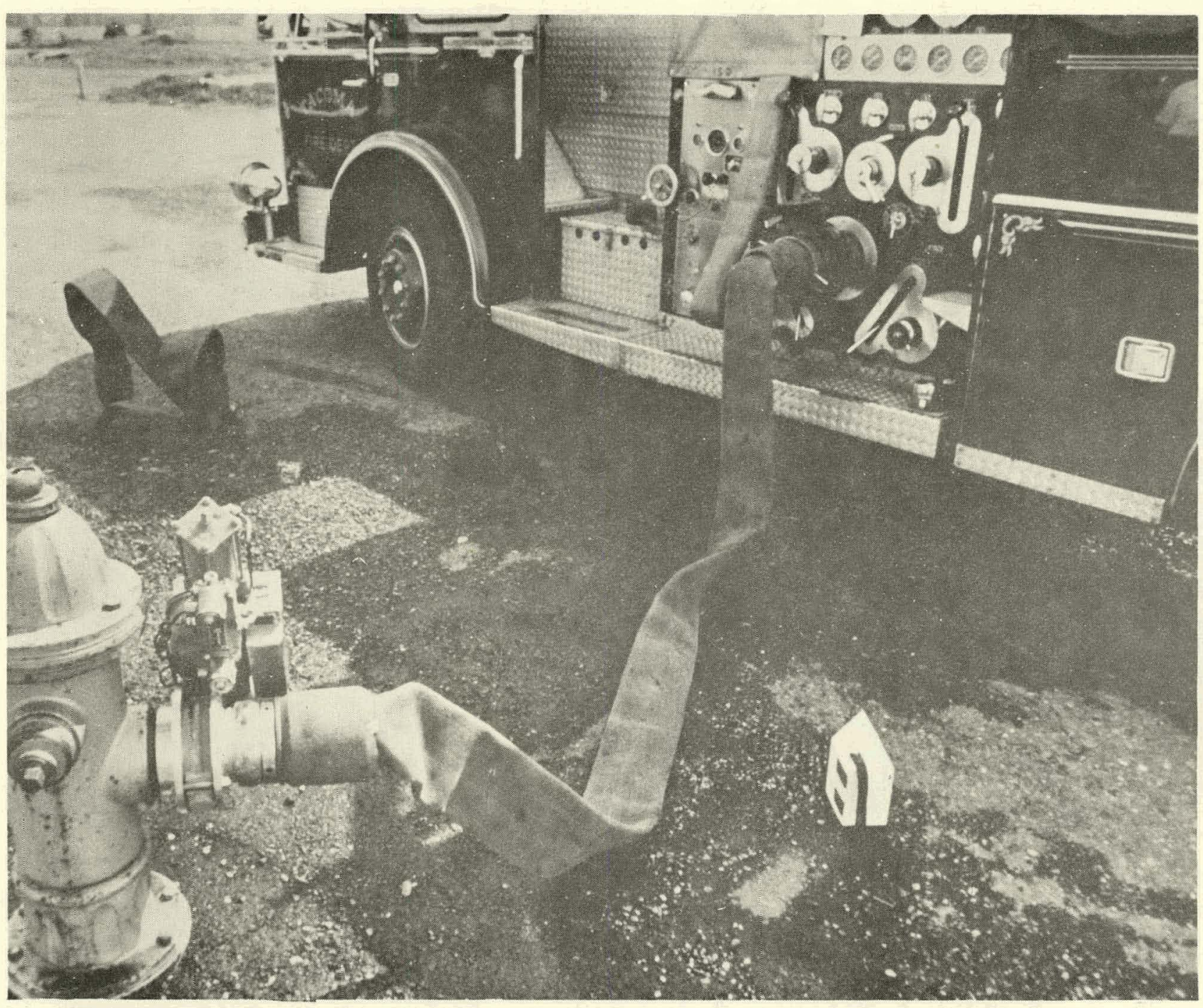

FIGURE 6. Remotely Controlled Hydrant Valve--First Approach 


\subsection{Second Approach}

A light-weight plastic butterfly valve was obtained. This was provided with a rotary actuator which has advantages of light weight and compactness.

A slightly lighter solenoid valve was obtained. A model airplane radio control system was used to operate the solenoid valve.

There are two rcasons for using the radio-controlled model. airplane system. It has a much longer range and permits equipment placement to provide more realistic demonstrations. ULilization of the servo mechanism with in-series contacts provides a very high degree of reliability against false signals. Each of the servo mechanisms requires a specific signal to move a certain distance. Putting two servos in series provides protection against false signals of an uncalculated but very high degree.

These components were mounted in a light-weight aluminum frame. The components included an air bottle so the valve could be actuated from a self-contained air supply. This feature was primarily to reduce the probability of operating failure from a muddy hydrant. However, using only compressed aix limits the system to one to three operations. The use of a low boiling-point liquid in this self-contained air supply could greatly increase the operational capability of the valve. The valve was also set up to be operated from hydrant pressure if desired.

Provision for manual override of the actuator was made by placing the valves in the supply lines to the actuator. The actuator used has an external stud which permits manual operation with a wrench. 
The weight of this assembly is $241 \mathrm{~b}$.

A schematic description of this valve is shown in Figure 7. A schematic of valve operation is shown in Figure 8 . The valve assembly is pictured in Figure 1.

This valve operated successfully from hydraulic pressure on its initial test. During one demonstration there was insufficient hydraulic pressure to fully activate the valve. A larger actuator was obtained, but in all experiments since that time, the valve has functioned properly so the larger actuator has not been installed. However, the possibility of very low hydraulic pressure should be considered in determining whether hydraulic pressure or a self-contained pressure reservoir should be used for valve actuation. The possibility of very dirty water should also be considered if hydraulic pressure is used for actuation.

A motor operation of the valve was attempted, using a friction clutch between the motor and the gear box. The friction clutch did not function well in the presence of water from the hydrant. Hence, this approach was not pursued. However, there are several questions as to whether a fluid-actuated valve or motor-driven valve might ultimately be best.

On the surface, the motor-driven valve has less chance of failure. A single set of contacts operates the motor which turns the valve. In the fluid-actuated system, the contact actuates the solenoid valve which then activates the fluid cylinder. A failure in the fluid supply (for example, if a low boiling-point fluid is used), a failure in the line between the supply and the solenoid valve, or the failure of an operator 
4" NYLON BODY BUTTERFLY VALVE, SEAT MATERIAL TFE, SHAFT STEEL, DISC IRON INSERT WITH MOLDED TFE COVER \& SEAT.

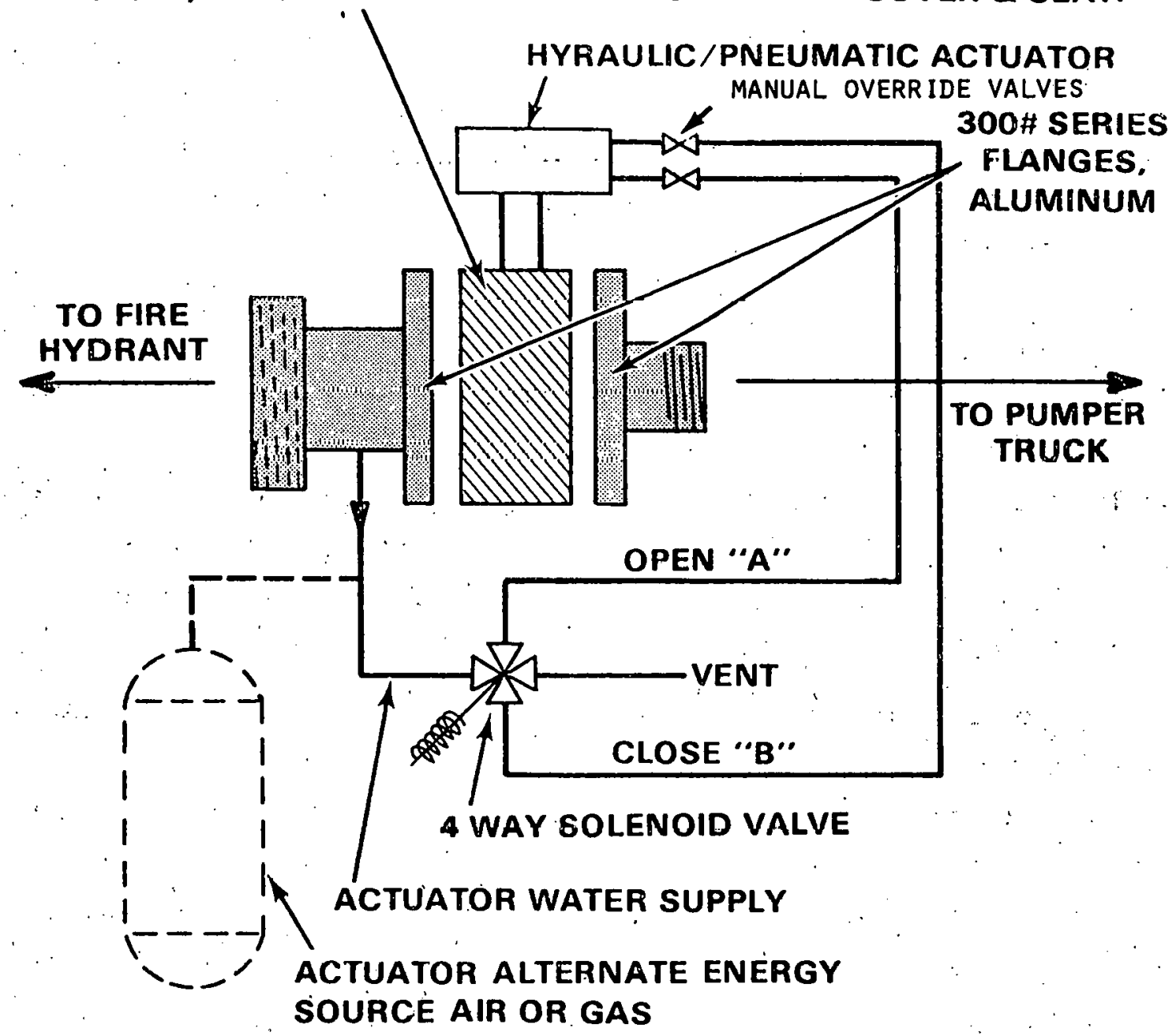

- MECHANICAL -

\section{EQUIPMENT \& MATERIALS NOT NOTED}

Transmittor, receiver and servo are standard model airplane controls. Electrical power supplies are all rechargeable. The alternate actuator energy source could be a small gas or air bottle capable of several operations and be field rechargeable.

FIGURE 7. Schematic Description of Hydrant Valve 
TRANSMITTER
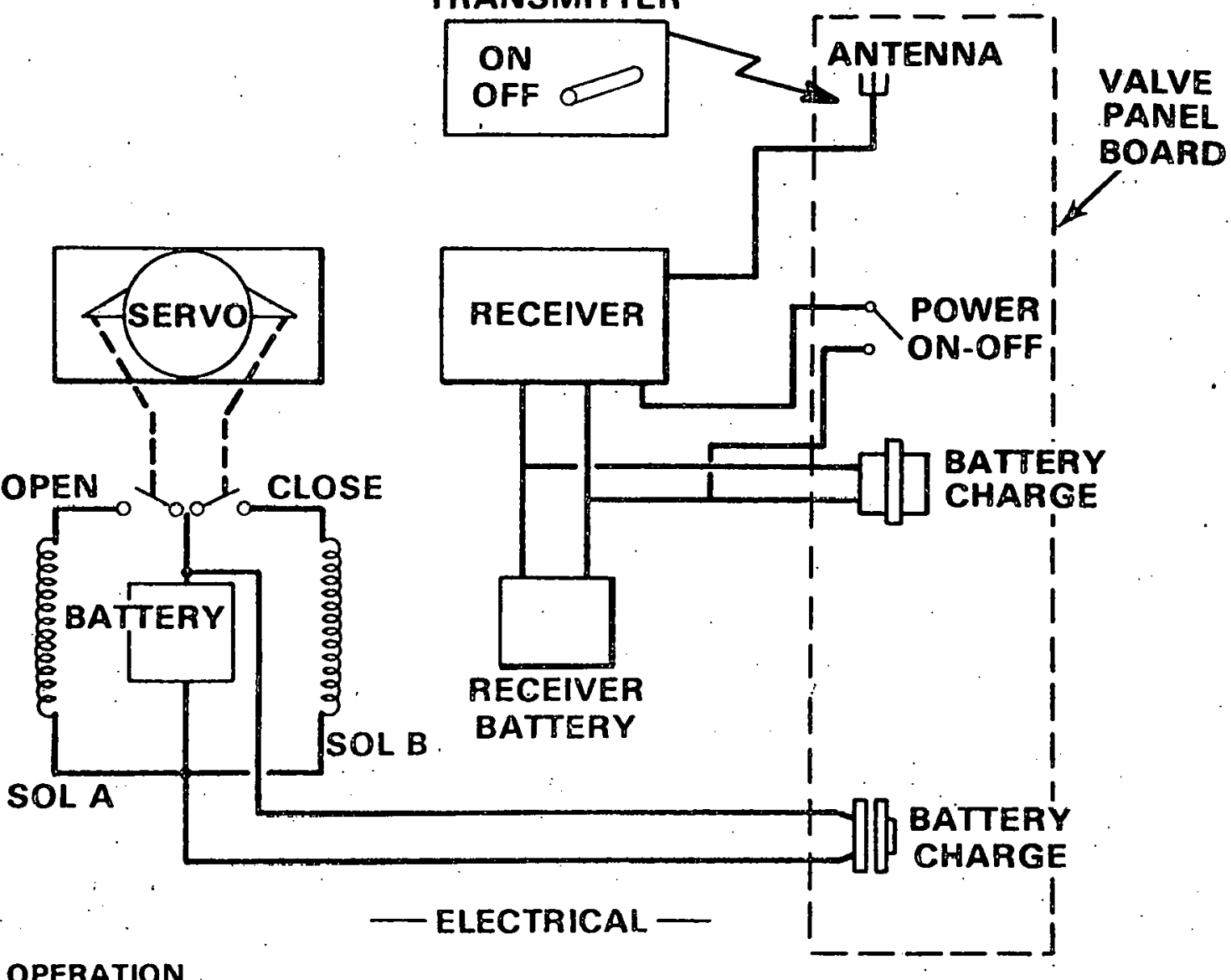

\section{OPERATION}

The automatic valve is connected to the fire hydrant in the closed position. The fire hydrant is manually opened supplying water main pressure to the four-way solenoid valve. From a remote position, for example at the pumper truck, the transmitter is turned to the "open " position. this radio signals the receiver which in turn drives the servo. The servo mechanically closes the open contacts on the open micro switch. This contact energizes the open solenoid " $A$ " allowing the hydrant water pressure to operate the valve actuator. The actuator turns the butterflyvalve shaft $90^{\circ}$ to an open position, pressurizing the pumper suction line. To close the butterfly valve the process is reversed by turning the transmitter to the "close" position. The vent in the solenoid allows the actuator to reverse pusitiun and an internal stop in the actuator prevents a rotation of inore than $90^{\circ}$.

FIGURE 8. Operation Schematic--Hydrant Valve 
to see that the battery was charged could cause this system to fail. With the motor-driven valve the same battery that actuates the solenoid can be the battery which drives the motor, so there is only one thing for the operator to check. 


\section{0 RESULTS}

The objectives of this work were achieved. It was shown that a light-weight (25 $\mathrm{lb}$ or less) radio-actuated valve could be built. An extrapolation from this to the reliability necessary for fire fighting operations seems reasonable. The prototype valve has been demonstrated to several groups and individuals concerned with fire fighting, and comment has been favorable in almost every instance. It appears that the remotelyoperated valve could become a commercial product in the near future. 


\subsection{ACKNOWLEDGEMENTS}

As previously noted, city of Tacoma personnel * were responsible for the automatic valve concept, for design assistance, and for testing and demonstration.

Eliwood Werry and Lowell strope of Battelle-Northwest provided invaluable engineering assistance. Michael Drumheller assisted in assembly and early testing.

*Principally, W. E. Donaldson, James Reiser, Tony Mitchell, Russ Nance, Harvey Singleton, and Regina Glenn, with contributions by many others. 


\section{DISTRIBUTION}

No. of

Copies

1 ERDA Chicago Patent Group 9800 South Cass. Avenue Argonne, IL 60439

A. A. Churm

27 ERDA Technical Information Center

1. City Manager 800 Central Avenue Cincinnati, OH 45202

W. E. Donaldson

1 Brookhaven National Laboratory Office of the Director Building 460 Upton, NY 11973

William L. Graves

1 Heath Tecna Corporation $1981984 \mathrm{th}$ Avenue S Kent, WA 98031

1 Union Carbide Corporation Nuclear Division P.O. Box 7 Oak Ridge, TN 37830

M. E. Koons

1 Lawrence Livermore Laboratory University of California P.O. Box 808 Livermore, CA 94550

R. Carroll Maninger

1 Sandia Laboratories - 9623 Technology Utilization Program Albuquerque, NM 87115

G. C. McDonald
No. of

Copies

1 Mine Safety Appliances 400 Penn Center BIvd. Pittsburg, PA 15235

1 Lawrence Berkeley Laboratory University of California Building 90, Room 1106 Berkeley, CA 94720 Robert J. Morris

1 Boeing Computer Sciences Center P.O. Box 3707 Seattle, WA 98124

Joe Muldoon

5. City of Tacoma City Hall 930 Tacoma Avenue Tacoma, WA 98402

James Reiser Tony Mitchell Russ Nance Harvey Singleton Regina Glenn

$1 \frac{\text { Snap-Tite, Inc. }}{201 \text { Titusvilie, }} \mathrm{Rd}$. Union City, PA 16438

1 Los Alamos Scientific Laboratory

University of California Box 1663

Los Alamos, NM 87544

Eugene Starkes

1 Argonne National Laboratory 9700 South Cass Avenue Argonne, IL 60439

John T. Venard 
No. of

Copies

1 ERDA Richland Operations

Office

70 Battelle-Northwest

K Drumheller (30)

R. P. Marshall

L. C. Schmid

E. V. Werry (30)

Tochnical Information (5)

Tcchnical Fublications (3) 